\title{
Effect of bowel obstruction on stage IV colorectal cancer
}

\author{
WEI CHEN ${ }^{1 *}$, XIAO-PING TAN ${ }^{2 *}$, JUN-WEN YE ${ }^{1 *}$, QIN LIU $^{3,4^{*}}$, \\ QINGLI ZENG ${ }^{5}$, LEI WANG ${ }^{1}$ and JIAN-PING WANG ${ }^{1}$

\begin{abstract}
${ }^{1}$ Department of Colorectal Surgery, The Sixth Affiliated Hospital of Sun Yat-sen University;
${ }^{2}$ Emergency Department, The Fourth Affiliated Hospital of Guangzhou Medical University, Guangzhou, Guangdong 510655;

${ }^{3}$ Chongqing Hospital of Traditional Chinese Medicine, Jiangbei, Chongqing 400021; ${ }^{4}$ Department of Pathophysiology,

Zhongshan School of Medicine, Sun Yat-sen University, Guangzhou, Guangdong 510080;

${ }^{5}$ Department of General Surgery, Jiangxi Provincial People's Hospital, Nanchang, Jiangxi 330006, P.R. China
\end{abstract}

Received October 14, 2013; Accepted December 19, 2013

DOI: $10.3892 / \operatorname{mco} .2014 .240$

\begin{abstract}
Colorectal cancer (CRC) is the third most commonly diagnosed cancer worldwide, with a high mortality rate, particularly among patients with advanced-stage disease complicated by bowel obstruction. The present study aimed to investigate the value of different surgical procedures and potential predictors of survival for patients with stage IV CRC, with or without bowel obstruction. Between August, 1994 and December, 2005, a total of 2,950 CRC patients were diagnosed and treated at our hospital. Among these, 381 patients had stage IV disease and were divided into two groups according to the presence $(n=295)$ or absence $(n=86)$ of bowel obstruction. The clinical data of all the patients with stage IV CRC were retrospectively analyzed and all the patients were followed up. Our results demonstrated statistically significant differences in gender, radical resection, histological type, ascites, tumor location, peritoneal and liver metastases between the obstruction and non-obstruction groups. We also observed that hepatic metastases and radical resection were factors associated with prognosis according to the univariate and multivariate analyses. Furthermore, the mean/median survival time was
\end{abstract}

Correspondence to: Dr Jian-Ping Wang or Dr Lei Wang, Department of Colorectal Surgery, The Sixth Affiliated Hospital of Sun Yat-sen University, 26 Yuancun Erheng Road, Guangzhou, Guangdong 510655, P.R. China

E-mail:wjp@mail.sysu.edu.cn

E-mail: leiwangyinghu@hotmail.com

Dr QingLi Zeng, Department of General Surgery, Jiangxi Provincial People's Hospital, 92 Aiguo Rd, Donghu, Nanchang, Jiangxi 330006, P.R. China

E-mail: qlzkz@163.com

${ }^{*}$ Contributed equally

Key words: colorectal cancer, stage IV, radical resection, obstruction
49.4/21.6 and 37.2/17.1 months in the non-obstruction and obstruction groups, respectively. In conclusion, obstruction was not found to be an independent indicator of survival for patients with stage IV CRC, with patients in the obstruction group exhibiting a worse overall survival compared to those in the non-obstruction group, whereas active radical surgery significantly improved the prognosis of patients with stage IV CRC.

\section{Introduction}

Colorectal cancer (CRC) is the third most commonly diagnosed cancer worldwide. Despite advances in diagnosis and treatment, CRC mortality has remained unchanged over the last 50 years and prognosis is closely associated with the disease stage at the time of diagnosis (1), with a 5-year survival rate of only $8 \%$ in patients with stage IV CRC (2).

Several patients develop bowel obstruction, which is a well-recognized complication of advanced-stage CRC, with an incidence of 7-47\% (3,4). Compared to those withnon-obstructive $\mathrm{CRC}$, the 5-year survival rate of patients with obstructive CRC was reported to be $20 \%$ (5-7). In addition, certain factors are significantly different between the two groups, including peritoneal metastasis, histological grade and recurrence. As regards the treatment of patients with stage IV CRC, opinions vary widely. For patients with complications, surgical treatment is required. The development of modern technology enables the effective treatment of a number of asymptomatic or minimally symptomatic patients with stage IV CRC. The major aims of therapy are to prolong survival and maintain the quality of life. Asymptomatic patients may be treated without resection in order to avoid complications and the risk of perioperative morbidity $(8,9)$. When compared to asymptomatic patients who underwent surgical resection, asymptomatic patients with distant metastasis who underwent resection exhibited no survival benefits (10). Kaufman et al (11) reported that patients receiving surgical resection, chemotherapy, or a combination of the two, had median survival times of 22, 15 and 30 months, respectively. In order to avoid local tumor complications and improve the chances of further treatment, some studies recommend palliative resection of the primary tumor in asymptomatic patients (12-14). 
Table I. Analysis of demographic, patient and pathological characteristics in patients with colorectal cancer, with or without bowel obstruction $(\mathrm{n}=381)$.

\begin{tabular}{|c|c|c|c|c|}
\hline \multirow[b]{2}{*}{ Characteristics } & \multirow[b]{2}{*}{ Cases } & \multicolumn{2}{|c|}{ Obstruction } & \multirow[b]{2}{*}{ P-value } \\
\hline & & No & Yes & \\
\hline Gender & & & & 0.003 \\
\hline Female & 227 & 164 & 63 & \\
\hline Male & 154 & 131 & 23 & \\
\hline Radical resection & & & & 0.005 \\
\hline No & 180 & 128 & 52 & \\
\hline Yes & 201 & 167 & 34 & \\
\hline Age (years) & & & & 0.165 \\
\hline$<60$ & 189 & 152 & 37 & \\
\hline$\geq 60$ & 192 & 143 & 49 & \\
\hline Family history & & & & 0.159 \\
\hline No & 367 & 282 & 85 & \\
\hline Yes & 14 & 13 & 1 & \\
\hline Blood transfusion & & & & 0.087 \\
\hline No & 186 & 151 & 35 & \\
\hline Yes & 195 & 144 & 51 & \\
\hline Histological type & & & & $<0.001$ \\
\hline Villous adenocarcinoma & 57 & 47 & 10 & \\
\hline Tubular adenocarcinoma & 262 & 210 & 52 & \\
\hline Mucinous adenocarcinoma & 39 & 30 & 9 & \\
\hline Signet ring cell tumor & 23 & 8 & 15 & \\
\hline Ascites & & & & $<0.001$ \\
\hline No & 295 & 222 & 73 & \\
\hline Yes & 86 & 41 & 45 & \\
\hline Tumor size $(\mathrm{cm})$ & & & & 0.041 \\
\hline$\leq 5$ & 221 & 180 & 41 & \\
\hline$>5$ & 160 & 116 & 44 & \\
\hline Tumor location & & & & $<0.001$ \\
\hline Colon & 147 & 115 & 32 & \\
\hline Rectum & 234 & 180 & 54 & \\
\hline Peritoneal metastasis & & & & $<0.001$ \\
\hline No & 331 & 279 & 52 & \\
\hline Yes & 50 & 16 & 34 & \\
\hline Hepatic metastasis & & & & $<0.001$ \\
\hline No & 285 & 240 & 45 & \\
\hline Yes & 96 & 55 & 41 & \\
\hline Histological differentiation & & & & 0.520 \\
\hline High & 40 & 33 & 7 & \\
\hline Moderate & 241 & 188 & 53 & \\
\hline Poor & 100 & 74 & 26 & \\
\hline
\end{tabular}

Although the effects of obstruction and surgery on survival were previously reported, the number of available studies investigating the factors of obstruction in patients with stage IV CRC in China is currently limited. Therefore, in the present study, we aimed to investigate bowel obstruction in patients with stage IV $\mathrm{CRC}$ and retrospectively analyze the clinicopathological characteristics and long-term outcomes for such patients.

\section{Patients and methods}

Study population. Between August, 1994 and December, 2005 a total of 2,950 patients were diagnosed with CRC and treated at the Sixth Affiliated Hospital of Sun Yat-sen University (Guangzhou, China). A total of 381 patients were diagnosed with stage IV CRC and were divided into two groups according 
Table II. Univariate analysis of patients with stage IV colorectal cancer $(n=381)$.

\begin{tabular}{|c|c|c|c|c|}
\hline \multirow[b]{2}{*}{ Variables } & \multicolumn{3}{|c|}{ Overall survival rate (\%) } & \multirow[b]{2}{*}{ P-value } \\
\hline & 1-year & 3 -year & 5 -year & \\
\hline Gender & & & & 0.194 \\
\hline Female & 95.6 & 87.8 & 78.9 & \\
\hline Male & 93.5 & 81.3 & 68.6 & \\
\hline Age (years) & & & & 0.235 \\
\hline$<60$ & 96.7 & 88.8 & 75.4 & \\
\hline$\geq 60$ & 98.3 & 83.8 & 71.5 & \\
\hline Family history & & & & 0.850 \\
\hline No & 97.5 & 92.4 & 87.3 & \\
\hline Yes & 48.6 & 20.8 & 20.8 & \\
\hline Histological type & & & & 0.796 \\
\hline Villous adenocarcinoma & 81.3 & 43.8 & 13.5 & \\
\hline Tubular adenocarcinoma & 96.5 & 90.8 & 82.9 & \\
\hline Mucinous adenocarcinoma & 71.5 & 22.0 & 22.0 & \\
\hline Signet ring cell tumor & 52.9 & 21.2 & 21.2 & \\
\hline Blood transfusion & & & & 0.373 \\
\hline No & 96.2 & 86.8 & 75.1 & \\
\hline Yes & 94.8 & 84.7 & 72.2 & \\
\hline Tumor size (cm) & & & & 0.362 \\
\hline$\leq 5$ & 95.4 & 87.8 & 76.8 & \\
\hline$>5$ & 94.4 & 82.2 & 69.5 & \\
\hline Tumor location & & & & 0.308 \\
\hline Colon & 94.6 & 85.7 & 73.1 & \\
\hline Rectum & 95.3 & 85.2 & 73.2 & \\
\hline Ascites & & & & $<0.001$ \\
\hline No & 96.6 & 91.1 & 82.2 & \\
\hline Yes & 92.2 & 73.5 & 83.3 & \\
\hline Peritoneal metastasis & & & & 0.290 \\
\hline No & 96.8 & 91.1 & 84.4 & \\
\hline Yes & 90.5 & 65.5 & 41.7 & \\
\hline Hepatic metastasis & & & & 0.010 \\
\hline No & 95.2 & 84.5 & 73.0 & \\
\hline Yes & 95.2 & 82.9 & 64.5 & \\
\hline Radical resection & & & & $<0.001$ \\
\hline No & 93.9 & 84.2 & 72.3 & \\
\hline Yes & 96.5 & 87.1 & 78.5 & \\
\hline Histological differentiation & & & & 0.630 \\
\hline High & 67.6 & 16.5 & 16.5 & \\
\hline Moderate & 94.6 & 84.6 & 73.4 & \\
\hline Poor & 94.9 & 83.3 & 67.8 & \\
\hline Obstruction & & & & 0.044 \\
\hline No & 96.9 & 90.7 & 84.3 & \\
\hline Yes & 89.2 & 64.1 & 34.4 & \\
\hline
\end{tabular}

to the presence $(n=295)$ or absence $(n=86)$ of obstruction. We retrospectively analyzed the clinicopathological characteristics of the CRC patients from a computerized database and the patients were divided into subgroups according to the recorded variables as follows: i) gender, age ( $<60$ and $\geq 60$ years) and family history; ii) tumor location (colon and rectum), tumor differentiation (well-, moderately and poorly differentiated adenocarcinoma) and tumor size ( $\leq 5$ and $>5 \mathrm{~cm}$ ); iii) blood 
Table III. Multivariate analysis of factors associated with survival in patients with stage IV colorectal cancer.

$95 \%$ CI for $\operatorname{Exp}(\mathrm{B})$

\begin{tabular}{lccccccrr} 
Factors & $\mathrm{B}$ & $\mathrm{SE}$ & Wald & df & Sig. & Exp(B) & Lower & Upper \\
\hline Obstruction & 0.262 & 0.152 & 2.953 & 1 & 0.086 & 1.299 & 0.964 & 1.752 \\
Ascites & 0.152 & 0.144 & 1.105 & 1 & 0.293 & 1.164 & 0.877 & 1.545 \\
Hepatic metastasis & 0.195 & 0.055 & 12.522 & 1 & $<0.001$ & 1.215 & 1.091 & 1.354 \\
Radical resection & 0.693 & 0.110 & 39.976 & 1 & $<0.001$ & 2.000 & 1.613 & 2.480
\end{tabular}

CI, confidence interval; SE, standard error; df, degrees of freedom; sig., significance.

transfusion, resection of the primary tumor, ascites, peritoneal metastasis and hepatic metastasis.

Statistical analysis. Patient survival was analyzed with the Kaplan-Meier method and the variables were compared using the log-rank test. A multivariate analysis of the patients was performed using the Cox proportional hazards model, which is mainly used in the analysis of survival data for investigating the association between patient survival and covariates (independent variables or predictors).

\section{Results}

Patients and tumor characteristics. The demographic, patient and pathological characteristics of CRC are summarized in Table I. The mean age of the patients was 58.18 years (range, 25-87 years) in the non-obstructive and 56.58 years (range, 19-87 years) in the obstructive CRC groups. The number of blood transfusions was similar between the two groups and there was no significant difference in survival rate between patients who received a blood transfusion and those who did not $(\mathrm{P}=0.373)$ (Table II). The overall survival rate was also compared by gender, family history of CRC, age, tumor size, tumor location, peritoneal metastasis, histological grade and histological type, but the differences were not found to be statistically significant (Table II).

Univariate and multivariate analysis of patients with stage IV $C R C$. The univariate prognostic factors in patients with stage IV CRC are summarized in Table II. Ascites $(\mathrm{P}<0.001)$, hepatic metastasis $(\mathrm{P}=0.010)$ and radical resection $(\mathrm{P}<0.001)$ were found to be associated with outcome in stage IV CRC. However, certain factors, including gender, age, family history, blood transfusion, histological grade and tumor location, were not found to affect survival. In the analysis of obstruction, the multivariate analysis demonstrated that obstruction, ascites, hepatic metastasis and radical resection were independent factors for the survival of patients with stage IV CRC (Table III).

Long-term outcomes. A comparison of the survival curves between the non-obstruction and obstruction groups is shown in Fig. 1. The mean/median survival time was 49.4/21.6 and $37.2 / 17.1$ months in the non-obstruction and obstruction groups, respectively. In the colon, the mean/median survival time was 54.4/21.4 and 48.0/17.8 months in the

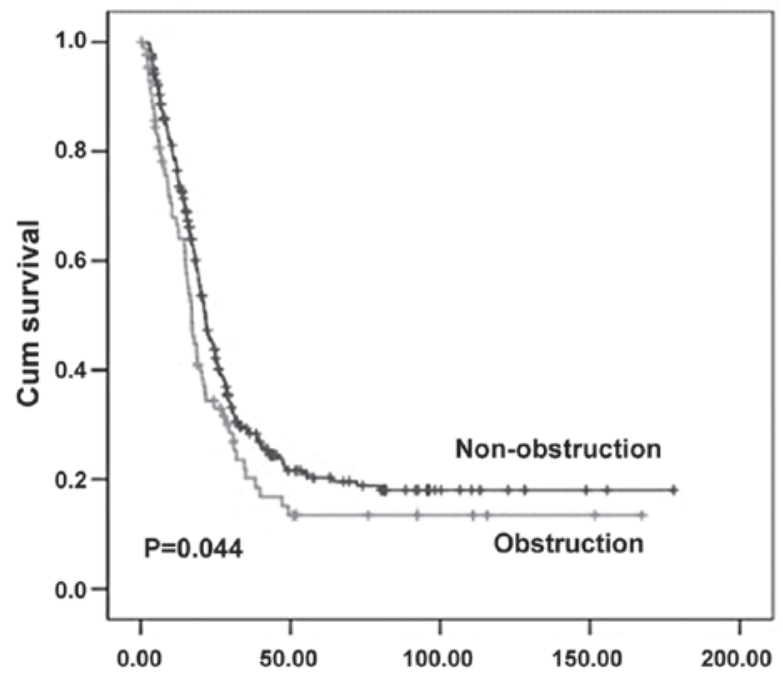

Figure 1. Survival curve for patients with stage IV obstructive and non-obstructive colorectal cancer. Cum, cumulative.

non-obstruction and obstruction groups, respectively. The overall 3- and 5-year survival rates were 90.7 and $84.3 \%$ in the non-obstruction group, respectively, and 64.1 and $34.4 \%$ in the obstruction CRC group, respectively.

\section{Discussion}

It was recently reported that tumor size is associated with the prognosis of CRC (15), which was inconsistent with our results. The fact that the appropriate cut-off values and the dynamic point of the optimal cut-off values were not taken into consideration in this study, may explain the fact that we were unable to verify the prognostic significance of tumor size.

In agreement with previous findings (16), in our study, the survival of patients with radical resection was better compared to that of the patients who had undergone non-radical resection, indicating that complete tumor resection is associated with prognosis in patients with stage IV CRC. The total number of patients with non-obstructive CRC was $295(\sim 77.4 \%)$ and the survival of patients with obstructive CRC was poor. A previous study reported that patients aged $<40$ or $>80$ years were at an increased risk of developing bowel obstruction (17). However, our study demonstrated that the percentage of patients with obstructive CRC and advanced cancer did not statistically differ 
between age groups. Similarly, the differences in survival did not approach statistical significance in the analysis by obstruction (Table III). However, obstructive CRC was associated with a poor prognosis and shorter overall survival according to the multivariate Cox regression model (Table III). This may due to the number of patients enrolled in this study. Similar conclusions were also reached by previous studies $(18,19)$.

According to our results, the survival of CRC patients with bowel obstruction is significantly associated with radical resection, ascites and hepatic metastasis. The overall 1-,3- and 5 -year survival rates were lower in the obstructive compared to those in the non-obstructive CRC group. However, bowel obstruction was not found to be associated with a poorer prognosis or shorter overall survival in the multivariate Cox regression model, which was a finding inconsistent with previously reported results (20). In addition, intestinal obstruction may occur at any site along the colon and rectum, while the risk of obstruction varies across the intestine. In our study, $27(31.3 \%)$ patients presented with bowel obstruction at the level of the rectum and $59(68.6 \%)$ patients had obstruction of the colon. This result was similar to those of previous studies $(21,22)$. In our study, the histological grade/type of CRC was not found to be an independent prognostic factor (Table II), which was different from previously reported findings (19). The difference observed in our study may be a result of the inconsistent grading criteria and grouping systems among different grades.

The presence of ascites was associated with prognosis in the analysis of obstruction and surgical treatment. Patients with ascites exhibited a significantly worse survival compared to those without ascites, which is consistent with previous findings (23). It is recommended that patients with ascites receive non-surgical treatment, such as hydration, corticosteroids and percutaneous gastrostomy (24). Moreover, the number of patients with hepatic metastases in our study was similar or higher compared to that reported by previous studies. This difference may be a result of the differences in tumor stage and histological type; for example, ulcerated tumors were reported to be associated with a higher metastatic risk (25).

There were some limitations to this study. The number of patients in our study was relatively small and, therefore, some factors associated with prognosis may have been overlooked. In addition, several factors were not investigated in this study, such as the levels of carcinoembryonic antigen and CA19-9, chemotherapy and perineural invasion. Furthermore, data regarding recurrence following surgery in patients with CRC were not available.

In conclusion, we demonstrated that certain prognostic factors may affect the outcome of patients with stage IV CRC, although obstruction was not found to be an independent indicator of survival. The patients with bowel obstruction had a poorer prognosis compared to those with non-obstructive CRC, whereas active radical surgery significantly improved the prognosis of patients with stage IV CRC.

\section{References}

1. Parkin DM, Bray F, Ferlay J and Pisani P: Global cancer statistics, 2002. CA Cancer J Clin 55: 74-108, 2005.
2. Jemal A, Siegel R, Ward E, et al: Cancer statistics, 2006. CA Cancer J Clin 56: 106-130, 2006.

3. Chen HS and Sheen-Chen SM: Obstruction and perforation in colorectal adenocarcinoma: an analysis of prognosis and current trends. Surgery 127: 370-376, 2000.

4. Lee YM, Law WL, Chu KW and Poon RT: Emergency surgery for obstructing colorectal cancers: a comparison between right-sided and left-sided lesions. J Am Coll Surg 192: 719-725, 2001.

5. Phillips RK, Hittinger R, Fry JS and Fielding LP: Malignant large bowel obstruction. Br J Surg 72: 296-302, 1985.

6. Ohman U: Prognosis in patients with obstructing colorectal carcinoma. Am J Surg 143: 742-747, 1982.

7. McArdle CS and Hole DJ: Emergency presentation of colorectal cancer is associated with poor 5-year survival. Br J Surg 91: 605-609, 2004.

8. Michel P, Roque I, Di Fiore F, et al: Colorectal cancer with non-resectable synchronous metastases: should the primary tumor be resected? Gastroenterol Clin Biol 28: 434-437, 2004.

9. Clements D, Dhruva Rao P, Ramanathan D, Adams R, Maughan TS and Davies MM: Management of the asymptomatic primary in the palliative treatment of metastatic colorectal cancer. Colorectal Dis 11: 845-848, 2009.

10. Scoggins CR, Meszoely IM, Blanke CD, Beauchamp RD and Leach SD: Nonoperative management of primary colorectal cancer in patients with stage IV disease. Ann Surg Oncol 6: 651-657, 1999.

11. Kaufman MS, Radhakrishnan N, Roy R, et al: Influence of palliative surgical resection on overall survival in patients with advanced colorectal cancer: a retrospective single institutional study. Colorectal Dis 10: 498-502, 2008.

12. Stelzner S, Hellmich G, Koch R and Ludwig K: Factors predicting survival in stage IV colorectal carcinoma patients after palliative treatment: a multivariate analysis. J Surg Oncol 89: 211-217, 2005.

13. Ruo L, Gougoutas C, Paty PB, Guillem JG, Cohen AM and Wong WD: Elective bowel resection for incurable stage IV colorectal cancer: prognostic variables for asymptomatic patients. J Am Coll Surg 196: 722-728, 2003.

14. Rosen SA, Buell JF, Yoshida A, et al: Initial presentation with stage IV colorectal cancer: how aggressive should we be? Arch Surg 135: 530-535, 2000.

15. Kornprat P, Pollheimer MJ, Lindtner RA, Schlemmer A, Rehak P and Langner $\mathrm{C}$ : Value of tumor size as a prognostic variable in colorectal cancer: a critical reappraisal. Am J Clin Oncol 34: 43-49, 2011.

16. Abdalla EK: Resection of colorectal liver metastases. J Gastrointest Surg 15: 416-419, 2011.

17. Wong SK, Kneebone A, Morgan M, Henderson CJ, Morgan A and Jalaludin B: Surgical management of colorectal cancer in south-western Sydney 1997-2001: a prospective series of 1293 unselected cases from six public hospitals. ANZ J Surg 75: 776-782, 2005.

18. Liang $\mathrm{H}$, Wang $\mathrm{XN}$, Wang $\mathrm{BG}$, et al: Prognostic factors of young patients with colon cancer after surgery. World J Gastroenterol 12: 1458-1462, 2006.

19. Hotokezaka M, Jimi S, Hidaka H, et al: Factors influencing outcome after surgery for stage IV colorectal cancer. Surg Today 38: 784-789, 2008.

20. Yang Z, Wang L, Kang L, et al: Clinicopathologic characteristics and outcomes of patients with obstructive colorectal cancer. J Gastrointest Surg 15: 1213-1222, 2011.

21. Sarela AI, Guthrie JA, Seymour MT, Ride E, Guillou PJ and O'Riordain DS: Non-operative management of the primary tumour in patients with incurable stage IV colorectal cancer. Br J Surg 88: 1352-1356, 2001.

22. Nash GM, Saltz LB, Kemeny NE, et al: Radical resection of rectal cancer primary tumor provides effective local therapy in patients with stage IV disease. Ann Surg Oncol 9: 954-960, 2002.

23. Jayne DG, Fook S, Loi C and Seow-Choen F: Peritoneal carcinomatosis from colorectal cancer. Br J Surg 89: 1545-1550, 2002.

24. Higashi H, Shida H, Ban K, et al: Factors affecting successful palliative surgery for malignant bowel obstruction due to peritoneal dissemination from colorectal cancer. Jpn J Clin Oncol 33: 357-359, 2003.

25. Manfredi S, Lepage C, Hatem C, Coatmeur O, Faivre J and Bouvier AM: Epidemiology and management of liver metastases from colorectal cancer. Ann Surg 244: 254-259, 2006. 